\title{
Virtual-assisted lung mapping: is it actually better than finger palpation?
}

\author{
Taichiro Goto \\ Lung Cancer and Respiratory Disease Center, Yamanashi Central Hospital, Yamanashi, Japan \\ Correspondence to: Taichiro Goto, MD. Lung Cancer and Respiratory Disease Center, Yamanashi Central Hospital, Yamanashi 400-8506, Japan. \\ Email: taichiro@1997.jukuin.keio.ac.jp. \\ Comment on: Yanagiya M, Sato M, Ueda K, et al. Preoperative lung surface localization for pulmonary wedge resection: a single-center experience. \\ J Thorac Dis 2020;12:2129-36.
}

Submitted Sep 16, 2020. Accepted for publication Dec 03, 2020.

doi: $10.21037 /$ jtd-20-2908

View this article at: http://dx.doi.org/10.21037/jtd-20-2908

I read with interest "Preoperative lung surface localization for pulmonary wedge resection: a single-center experience" by Yanagiya et al. (1).

This article reported on the efficacy and limitations of preoperative lung surface localization for wedge resection by analyzing computed tomography-guided percutaneous marking and virtual-assisted lung mapping (VAL-MAP) (1). Unsuccessful resection was defined as either resection with insufficient margins or the need for additional resection to obtain adequate margins for curative wedge resection. Unsuccessful resection occurred in $8.2 \%$ of patients who underwent VAL-MAP. In this context, the authors concluded that the requirement for deeper resection was one of the limitations of preoperative lung surface localization for curative pulmonary wedge resection (1).

These points may warrant further consideration. VALMAP does not allow the direct marking of tumors; it only provides indirect information regarding the tumor location (1). The operators cannot directly determine the tumor location by touch; they can only estimate it using three-dimensional virtual image reconstruction. When performing wedge resection of the lung using video-assisted thoracic surgery, a surgical stapler is used. There is a risk of error in the staple line direction, as there are no objective indices for determining the depth and the direction, or vector, of the tumor. In VAL-MAP, the operators must determine the direction and distance of the staple cut line on an empirical basis while facing an uncertainty. Therefore, it is easy to understand that, if the direction estimated is close to the tumor, the margin is lost, which may result in incomplete resection with an inadequate margin. For tumors far from the surface, the required resection depth as defined by the authors becomes greater, and the surgical margin becomes unclear (1). When performing partial resection for small lung cancers, an adequate surgical margin is the most important oncological factor for curative resection (2-4); it may not be prudent to perform minimally invasive surgery by reducing the likelihood of curative resection. The study results indicated that the unsuccessful resection rate was relatively high at $8.2 \%$, which I think is the greatest weakness of VAL-MAP. In contrast, conventional finger palpation allows for the precise localization of tumors and determination of the cut line that allows for an adequate margin (5). We believe that the finger palpation method enables operators to perform curative resection to the maximum extent with confidence and safety. Therefore, we question whether VAL-MAP is more beneficial to patients than the finger palpation method.

It appears that the authors of this article performed additional resection for unsuccessful cases by confirming the margin intraoperatively, suggesting that the tumors were actually palpable. In this regard, we are interested in the percentage of palpable tumors in patients undergoing surgery using VAL-MAP. In our experience, most tumors are palpable, even in case of pure ground-glass neoplasms. We believe that the acquisition of palpation skills is essential for surgeons. If the tumor is palpable, the operator can identify the location of the tumor by simply inserting a finger into the chest cavity, which enables curative resection without VAL-MAP (5). 
The finger palpation method has the following advantages. When a tumor is not palpable with one or two fingers, especially when it is far from the surface, the feasible countermeasures are: (I) to widen the wound so that the operator's hand can be inserted into the chest cavity, enabling more accurate palpation through which the cut line is reset; or (II) to change the surgical method to segmentectomy or lobectomy when it is difficult to obtain an adequate margin (when the tumor is in a more central location). Thus, finger palpation is a flexible method that allows changing the cut line or the surgical method to ensure curability, even when a tumor is not palpable with one or two fingers. On the other hand, the current VALMAP technique does not involve palpation; the operators must perform resection based on indirect information regarding the location of the tumor, even when it is deep, and uncertainty remains regarding curability. Moreover, when compared to finger palpation, VAL-MAP is difficult to perform at some institutions; the technique requires additional materials, skilled staff, and more expensive equipment. VAL-MAP involves a fairly elaborate and invasive procedure, and there is a risk of reducing the likelihood of curative resection.

VAL-MAP is a bronchoscopic lung marking technique (using indigo carmine) that is not considered an essential preoperative procedure in conventional surgery. We suggest that the invasiveness and potential complications of the procedure may not be negligible from a comprehensive clinical perspective. Typically, a $\sim 3-\mathrm{cm}$ incision is needed in the finger palpation method, but the number of incisions is low (two for surgery using finger palpation in our institution; approximately three incisions for surgery using VAL-MAP). In our institution, we have been using the finger palpation method for all patients undergoing wedge resection for small lung cancers. The operative time is 20-30 min, and the length of postoperative hospital stay is $2-3$ days. To date, we have never encountered serious complications. Do the authors consider VAL-MAP to be a minimally invasive procedure compared to the finger palpation method?

Unsuccessful resection in this study was arbitrarily defined by the authors. According to their definition, the unsuccessful resection rate was relatively high at $8.2 \%$, suggesting that the method may be ethically unacceptable in clinical practice. If the authors wish to standardize this method in the future, they need to analyze the location of minimal margins in surgeries using VAL-MAP and develop countermeasures. Detailed investigation of the postoperative local recurrence rate and long-term prognosis is also needed. We hope the authors will conduct a randomized clinical trial to compare the safety, efficacy (curativity), and invasiveness of VAL-MAP with those of finger palpation.

New techniques are constantly evolving in the field of surgery. However, modern is not always better. Indeed, many new techniques have been found to be inferior to conventional techniques and have since disappeared. The utility of VAL-MAP remains under investigation. We suggest a more cautious approach is needed to determine the clinical validity of this new technique.

\section{Acknowledgments}

Funding: None.

\section{Footnote}

Provenance and Peer Review: This article was a free submission to the journal. The article was sent for external peer review.

Peer Review File: Available at http://dx.doi.org/10.21037/ jtd-20-2908

Conflicts of Interest: The author has completed the ICMJE uniform disclosure form (available at http://dx.doi. org/10.21037/jtd-20-2908). The author has no conflicts of interest to declare.

Ethical Statement: The author is accountable for all aspects of the work and is ensuring that questions related to the accuracy or integrity of any part of the work are appropriately investigated and resolved.

Open Access Statement: This is an Open Access article distributed in accordance with the Creative Commons Attribution-NonCommercial-NoDerivs 4.0 International License (CC BY-NC-ND 4.0), which permits the noncommercial replication and distribution of the article with the strict proviso that no changes or edits are made and the original work is properly cited (including links to both the formal publication through the relevant DOI and the license). See: https://creativecommons.org/licenses/by-nc-nd/4.0/.

\section{References}

1. Yanagiya M, Sato M, Ueda K, et al. Preoperative lung 
surface localization for pulmonary wedge resection: a single-center experience. J Thorac Dis 2020;12:2129-36.

2. Goto T. Measuring Surgery Outcomes of Lung Cancer Patients with Concomitant Pulmonary Fibrosis: A Review of the Literature. Cancers (Basel) 2018;10:223.

3. Mohiuddin K, Haneuse S, Sofer T, et al. Relationship between margin distance and local recurrence among patients undergoing wedge resection for small $(</=2 \mathrm{~cm})$ non-small cell lung cancer. J Thorac Cardiovasc Surg

Cite this article as: Goto T. Virtual-assisted lung mapping: is it actually better than finger palpation? J Thorac Dis 2021;13(1):414-416. doi: 10.21037/jtd-20-2908
2014;147:1169-75; discussion 75-7.

4. Wolf AS, Swanson SJ, Yip R, et al. The Impact of Margins on Outcomes After Wedge Resection for Stage I Non-Small Cell Lung Cancer. Ann Thorac Surg 2017;104:1171-8.

5. Ishida H, Yanagihara A, Taguchi R, et al. NEWS technique: easy and reliable thoracoscopic wedge resections of lung tumors. J Thorac Dis 2020;12:4571-7. 